\title{
Una mirada personalista de la novela Apolonio de Gustavo González Villanueva
}

\section{A selfish glance of the novel Apolonio by Gustavo González Villanueva}

\author{
Gabriel Quesada Mora \\ Editorial Promesa \\ Costa Rica \\ info@promesacultural.com
}

\begin{abstract}
Resumen
Se analiza en esta ponencia la novela corta Apolonio. Un político dentro de la posible realidad de América Latina del escritor guatemalteco Gustavo González Villanueva, a la luz del método lúdico-ambital desarrollado por el filósofo español Alfonso López Quintás. Se hace énfasis en los conceptos de objeto/ámbito, vértigo/ éxtasis. Además, se exploran temas personalistas como la razón, la fe y las relaciones humanas. Esta novela pone en juego una dinámica existencial en sus personajes lo que le procura una densidad filosófica personalista en medio de una estructura novelesca.
\end{abstract}

Palabras claves: Apolonio, personalismo, vértigo, éxtasis, objeto, ámbito, afectividad, razón, feo, novela guatemalteca

\begin{abstract}
The article consists of an analysis of the short novel Apolonio. Un politico dentro de la possible realidad de América Latina, written by the Guatemalan Gustavo González Villanueva, according to the "lúdico-ambital" method, develop by the Spanish philosopher Alfonso López Quintás. We emphasize the concepts of object/ambit and vertigo/ecstasy. Besides, we explore selfish
\end{abstract}


themes like reason, faith, and human relationships. This novel plays with an existentialist dynamics regarding the characters thar vecome a philosophical selfish density in a novelistic structure.

Keywords: Apolonio, personalism, vértigo, ecstasy, object, ambit, affection reason, faith, Guatemalan novel

\section{Introducción}

L os principales conceptos y temas de la filosofía personalista (la conciencia, la libertad, la corporeidad, la afectividad, la inteligencia, la trascendencia) que se empezó a desarrollar y a consolidar con más rigor académico en el periodo de 1930-1970, y que ha tenido un nuevo despertar en los últimos 20 años, son muy útiles para acercarse a los textos literarios y extraer de ellos importantes lecciones éticas al mismo tiempo que se evidencian sus riquezas estéticas. Un buen texto literario tiene la virtud de traducir en un lenguaje nuevo las mismas preocupaciones universales de todos los tiempos: el poder, el amor, el odio, la solidaridad, el sentido de la vida, entre otros. Aunado a lo anterior, un buen texto literario logra con excelencia estética darle vida a los conflictos que surgen de dichos temas universales, sabe darles un rostro y una expresión única a las disyuntivas existenciales de los personajes. Un buen texto literario sacude, rasga, golpea al lector y al final le procura una mirada más profunda que le permite continuar su camino con más propiedad y riqueza.

La novela que analizaremos: Apolonio. Un politico dentro de la posible realidad de América Latina (2016) tiene los elementos necesarios para abordarla desde una mirada personalista, ya que cuenta con varios conflictos individuales, sociales y existenciales que evidencian la complejidad de la condición humana. Esta novela corta tiene tres historias principales: la de Apolonio Andújar, la de Frederick y la de W. Mattinson.

Apolonio es un hombre que con astucia ha llegado a construirse cierta fama de buen abogado; es un hombre calculador, solo, frío, interesado, ateo, no tiene amigos, vive en la inmediatez, está lleno de odio y de orgullo. La novela muestra su camino de encumbramiento humano y su caída; al final es un títere más dentro de un engranaje de poder y dinero.

La segunda historia es la de Frederick, hermano menor de Apolonio. Él no estudió, desde joven también vivió resentido por la pobreza de su hogar, abandonó a su mujer y a su hijo y fue a buscar suerte en el ejército; en la selva vivió el horror de la muerte y de manera consciente mató a un hombre que tenía familia. Lleno de odio y de envidia hacia su hermano Apolonio planea su secuestro, no lo consigue, pero obtiene una gran suma de dinero al vaciar varias cuentas de su hermano. Es perseguido por la policía por el secuestro de un colega de Apolonio. Tras varios meses en 
fuga, se encuentra con un grupo de campesinos que van camino al Santuario del Cristo de Esquipulas; en ese recorrido vive una intensa tormenta interior entre la envidia, el odio y la culpa, hasta que parece entrar en un camino de conversión gracias a la ayuda del abad del Santuario que le planteó seriamente temas existenciales como el perdón, el amor y la libertad.

Por último, la historia de Mattinson que es un hombre que controla un periódico influyente del país, pero él -al igual que Apolonio- vive de acuerdo con la inmediatez, el cálculo político y económico; sin embargo, fracasa en su intento de sacar adelante su periódico y es eliminado por una "fraternidad" secreta que controla el poder en el país. Estas dos historias (la de Frederick y la de Mattinson) convergen en el personaje de Apolonio que actúa en ambas con su misma lógica interesada y llena de odio. En este trabajo nos enfocaremos principalmente en la historia de Apolonio y los conflictos que surgen en su entorno en los temas de la razón, la fe, el vértigo del poder, la manipulación y la mentira, las relaciones humanas de plenitud o soledad, todo esto a la luz de los conceptos de análisis literario que el método lúdicoambital del Dr. Alfonso López Quintás ha desarrollado para los estudios del personalismo literario.

\section{El conflicto entre la razón y la fe}

En las primeras páginas de la novela se nos presenta a un Apolonio muy seguro de sí mismo. El narrador da cuenta de sus calidades profesionales de abogado y catedrático (11) y de la buena fama que tiene en la sociedad. Es un hombre cerebral que idolatra la razón de forma extrema y, por consiguiente, desprecia todo lo relacionado con la religión de la que no tiene experiencia auténtica por su propia coraza de "razón" y "realidad". Esta actitud de idolatrar la razón y desacreditar el ámbito religioso de manera categórica es parte constitutiva de Apolonio, es ya un hábito que lo lleva tener una mirada maniquea de la realidad en este aspecto: para Apolonio la razón es el único medio para acceder al conocimiento verdadero, la fe religiosa no es para él algo razonado, por tanto, lo que surge de ella lo considera una pura ilusión. Esta consideración es una actitud objetivante, ya que considera la razón y la fe como meros objetos de uso. Entendemos el concepto de objeto como "realidades cerradas" que no ofrecen mayores posibilidades creativas y que tienen un valor de medio. Un objeto tiene el valor propio de su realidad material. Con esta estructura mental se mueve Apolonio en el mundo, esta es su máscara maniquea -cuando le conviene- que lo hace entrar en colisión con otras personas como su esposa Dalia que es una mujer de fe; Apolonio la desacredita y la rebaja de nivel porque considera que ella no es una mujer de "razón" y con ácido en sus palabras le dice: "pero mentalmente sigues siendo la alumnita de las monjas y la hijita de mamá" (12). Como se observa, la ridiculiza como modalidad para desacreditar sus pensamientos y sus acciones, recurre al pasado y la infancia para configurar una imagen de un ser inmaduro, que no creció con criterio propio. Sin embargo, la respuesta de Dalia es fulminante: "Si te molesta tanto, ¿por qué te casaste conmigo?" (12). Apolonio que es todo "razón" se casó con una mujer de baja categoría intelectual (según sus 
propios criterios), lo cual indicaría entonces una falta de inteligencia de Apolonio u otros motivos ocultos.

Continuando con este aspecto, Apolonio presenta una relación inmediata entre "lo racional" y "lo real" como se evidencia en estas líneas:

- Todo lo racional es real, todo lo real es racional. -Era lo primero que había escuchado en la clase de Filosofía del Derecho-. Entonces no lo comprendió; pero ahora lo veía con una claridad única que le envanecía. Se veía superhombre. (41).

Veamos que a partir de este presupuesto del pensamiento de Apolonio se deja por fuera toda experiencia o conocimiento que proceda de otras fuentes distintas a la razón. La razón es una facultad humana muy importante pero no puede abarcar, explicar o comprender todo lo existente. De manera que la realidad de algo no depende de la capacidad racional del sujeto que lo intenta aprender desde la razón. Las realidades religiosas hacen uso tanto de la razón, como de la intuición y de la experiencia personal. Lo anterior se relaciona con el personalismo literario en vista de que para este la realidad es una sola en dos dimensiones: la visible (realidad material) y la invisible (realidad inmaterial y trascendente). Por esto, la razón y la fe no deberían oponerse, sino que son dos maneras diferentes de acercarse a la misma realidad; no son excluyentes sino complementarias. Ya lo recuerda Vittorio Messori al indicar que "lo contario a la fe no es la razón, sino la superstición”. Y por su parte, como lo recuerda Mires siguiendo a Ratzinger: una razón sin fe ( $\sin$ criterios morales) es el fin mismo de la razón (183). Sin embargo, Apolonio vive sumergido en su razón absoluta desde la cual otorga realidad o validez a lo que lo rodea. Esto se comprende también a la luz de que Apolonio es un claro ejemplo de pensador positivista que busca siempre la comprobación inmediata, el hecho material, los números, el método científico; por eso no es gratuito que de manera reiterada lo veamos recurrir al pensamiento de Kant, de Hegel y de Nietzsche para apoyar sus ideas y acciones.

Por todo lo anterior es que vemos en esta novela que Apolonio no puede ascender del nivel de los meros objetos al nivel de los ámbitos que son "realidades abiertas" que son fuente de posibilidades. Ambitalizar es cuando se eleva de rango una realidad objetiva y se convierte en algo único. Un ámbito, según López Quintás, “es una realidad que no puede ser delimitada, pesada, asida... pero muestra una gran eficiencia" (1996: 190), ya que constituye un campo de realidad, algo difuso, ambiguo, que se extiende y abarca un espacio concreto (un campo de juego) en el cual se van interconectando diversos campos entre sí: lo biológico, lo ético, lo estético, el religioso, el cultural, etc. (190). La razón y la fe ciertamente son realidades que pueden ser ámbitos creativos, campos de juego que pueden enriquecer la comprensión de la realidad. Sin embrago, en el caso del personaje de Apolonio se observa que no es capaz de dar este paso, en contraposición con otros personajes como su esposa, sus padres y el abad Gregorio que sí logran poner en comunicación la razón y la fe. 


\section{El vértigo del poder, la manipulación y la mentira}

En el nivel humano, Apolonio es un ser exitoso en gran parte de su vida: abogado, catedrático, luego con doctorados honoris causa, magistrado, candidato presidencial. Sin embargo, ha escalado en la esfera social a partir de sus máscaras, la mentira, la manipulación y el interés propio: esto se encuentra dentro de la lógica del vértigo que desde la propuesta del método lúdico-ambital de Alfonso López Quintás es propio de la persona que actúa "en función del mero halago instintivo que implica empastarse con la realidad estimulante" (1996: 28). Esta actitud hace que la persona no tome la distancia necesaria para una opción reflexiva. Además, el ideal del vértigo es "dominar para disfrutar" (103). Apolonio desde joven decide conducir su vida de manera vertiginosa; muestra de ello es lo que le dice a su madre cuando queda viuda:

- Yo tengo la solución. Yo sé lo que usted debe hacer. Para esto he ido a la universidad, he estudiado, he tratado a mucha gente y sabido de muchos casos como el suyo. Lo que usted debe hacer es salir de este rincón de recuerdos que la ahogan; compartir la vida que le quede, con otras personas de su edad y tener quién la atienda: la comida, la ropa, las medicinas. (32).

Manipula su discurso y lo presenta como la mejor opción, con caridad de hijo y motivos razonables. Pero lo cierto es que lo que busca es beneficiarse económicamente y evitarse la incomodidad de tener que cuidar a su madre. Esta máscara es totalmente vertiginosa ya que no mira a la persona -su madre- como un ser sino como un objeto que estorba en sus planes. Esta manipulación la lleva más allá cuando logra engañar al padre Jean para que le ayude como intercesor ante las mojas que atienden el hogar de ancianos, le miente al padre Jean al insinuarle que él piensa seriamente en la posibilidad de entrar al Seminario (36). Todo es una farsa, tres meses después el sacerdote confirma el engaño cuando la hermana Genoveva le dice: "El hijo ha desaparecido. Los datos que nos dejó son falsos, y nadie ha venido a pagar los gastos de estos meses, como nadie ha venido a ver a la señora" (39). Y el cuidador y jardinero de la que fue la casa de los papás de Apolonio termina de darle al padre Jean la confirmación al indicarle que "hace tres meses que encerró a la mamá en un asilo de ancianos para poder vender la casa. Mejor dicho: ya la había vendido. Apolonio vive en otra ciudad o muy probablemente, según dicen, se fue del país" (39). La mentira como recurso para conseguir los fines, con la máscara de verdad, lleva a Apolonio a creer que el fin justifica los medios; en un mundo que considera relativo - en el que todo está permitido- acomoda sus acciones y sus pensamientos y valora todo a partir del criterio de la utilidad, criterio desprovisto de trascendencia $\mathrm{y}$ hondura, criterio plano y espurio.

Otro ejemplo de esta manipulación y engaño lo vemos en el origen del matrimonio de Apolonio con Dalia cuando el narrador dice que además de la joven Dalia, Apolonio "veía el ingenio de azúcar de la familia; la mirada mansa, como la de un buey de don Danilo, el papá de Dalia. La mamá, doña Carmen, no contaba" (12). Apolonio es calculador, esta es otra característica de 
una persona vertiginosa, mide, pesa, calcula, busca una ganancia. Esta actitud se vincula de nuevo con el trato de "objeto" hacia las personas; Dalia vale por el respaldo económico de su familia, no por sus propias capacidades y por su ser persona. Igualmente sus padres, para Apolonio son "objetos" que le estorban o que le pueden servir para conseguir sus fines.

Apolonio vive en esta experiencia de la manipulación, pero, así como él manipula, otros que están más arriba lo utilizan a él, como es cuando el "comité central" de la coalición de partidos de izquierda lo escogió para ser el candidato a la presidencia de la república. Apolonio está consciente de que lo utilizan, pero accede porque es más fuerte su deseo de poder, de figurar y ser alguien "importante". Apolonio es comprado como se puede comprar cualquier objeto, e incluso su asentimiento es tan rastrero como lo muestra el narrador en estas líneas:

Faltaban dos años para las elecciones y entendía claramente que debía disponerse a abandonar muchas de sus ideas, acostumbrarse a la incoherencia y a fingir convicciones y principios que hasta ahora había rechazado. Qué importancia pueden tener principios, convicciones, valores, cuando se presenta la oportunidad de alcanzar el éxito que supone un cargo público codiciado por tantos. Poder, dinero, honra, reconocimientos, entrada en la historia... (136)

Apolonio, aunque orgulloso, se rinde al ofrecimiento; él también tiene un precio, las convicciones que antes defendía, las fuerzas de su razón se ven endebles frente al placer que le genera el ejercicio de un poder que desea. Véase aquí de nuevo esta lógica de la utilidad y el placer como criterios para la acción humana. Apolonio es un peón, una pieza más en el gran juego del poder. Pero el vértigo se muestra también en el hecho de que cada vez más Apolonio y sus superiores necesitan nuevas experiencias de más poder y más placer, quieren cada vez más, y esto implica volver a las mismas fórmulas: manipular, mentir, comprar, botar. Es un círculo de violencia tremenda que puede encumbrar a las personas por un momento, pero al final la caída es inevitable como en el caso de Apolonio, que termina encerrado en la cárcel en la que "la risa y la burla de los presos le hacen entender que "el fenómeno Apolonio" solo ha sido una pesadilla... ¡otro pelotazo!... que ahora vive, despierto, en la cárcel. No, no es razonable, pero es la realidad" (146). Así, Apolonio al final es humillado, pisoteado, todo en lo que confiaba: la inteligencia, el dinero y el poder no le sirven de nada, está desprotegido, fue utilizado y ahora no tiene dónde poner su confianza, ha recibido los frutos del vértigo que son la tristeza, la desesperación y la destrucción. Destrucción total que primero sufrió el personaje del señor Mattinson que fue asesinado por sus "hermanos" del poder en una explosión de su automóvil. El vértigo es infecundo, no genera relaciones de afecto positivo y condena a las personas a la muerte material y espiritual.

\section{El ser relacional: entre la plenitud y la soledad}

La filosofía personalista resalta la importancia de las relaciones afectivas para la vida humana. Si para Aristóteles la relación 
es el último de los accidentes (para las cosas), en el caso de la persona humana es un elemento constitutivo, central. El ser humano es un ser hecho -biológica, social y trascendentemente- para establecer un diálogo, unos lazos afectivos con otros seres personales. La plenitud personal, como lo indica Domínguez Prieto, "solo ocurre en el encuentro con los otros, en tanto que son impulsantes, posibilitantes y apoyo" (23). En el caso de Apolonio, este decide no construir relaciones afectivas con las personas de su entorno, desde sus padres, sus hermanos, su esposa e hijo, sus colegas, etc. No hay ninguna relación de afecto auténtica, desinteresada y generosa. Apolonio con su mirada calculadora no está abierto al encuentro personal. Recordemos aquí que el encuentro más fecundo es el que se puede cultivar entre seres personales que están abiertos a la realidad de las otras personas, que aceptan su realidad propia y comprenden la novedad y riqueza del otro, de ese tú. En la novela se nos manifiesta que Apolonio:

No experimentaba ningún sentimiento ni ningún remordimiento. Cruzó las piernas y volvió a paladear y a saborear. Ni feliz ni infeliz. Podía desconocer y rechazar a sus padres. Para llegar al odio faltaba poco. Sus hermanas y hermanos no contaban: los odiaba desde siempre, ya que siempre los consideró sus competidores y emuladores. (28)

Desde joven, Apolonio decidió encerrarse en su propio caparazón; el narrador nos cuenta cómo esta relación tan distante surgió por la actitud rencorosa de Apolonio de ver en sus padres la razón de su pobreza y en sus hermanos, objetos que obstaculizaban sus fines. Así el panorama, Apolonio no quiere formar relaciones afectivas, lo que a mediano y largo plazo hace que alrededor de él se forme un desierto relacional que produce cada vez más una soledad profunda y pesada. "Soledad ambulante" (29) dice el narrador porque, en efecto, al no establecer lazos de afecto anda de un lugar a otro usando a las personas, no hay la necesaria apertura para echar raíces en el corazón de otras personas, la soledad se va haciendo más grande junto con el orgullo y el odio, no hay lugar en su vida sino solo para sí mismo.

Con su hijo y su esposa, Apolonio tiene más bien desencuentros, choques que hacen más grande la distancia emocional entre ellos. Con Dalia no hay ninguna muestra de afecto, de amor, discuten por asuntos religiosos y sociales. Con su hijo se establece la relación de poder y necesidad de proveedor-cliente. Hasta que su hijo llega a decirle “ Soy ateo! ¡Te odio!” (54), y se marcha de inmediato dejando una escena de completo cisma. Ante este tipo de eventos Apolonio se encierra más en sí mismo, en su odio y en su orgullo.

En el trabajo y en los demás espacios externos, Apolonio se dirige de igual manera; si se acerca a alguna persona y si parece decir algo afectuoso no es más que un recurso de manipulación inmediata para un fin personal. Así se conduce de manera hipócrita con los Mattinson, los García Lezama, los del Comité Central del Partido. Al decidir moverse de esta manera va creciendo en Apolonio un vacío existencial propio de los seres que viven en la inmediatez y el vértigo. 
En la novela sí hay ejemplos de relaciones afectivas valiosas, como el amor matrimonial de los padres de Apolonio, que en medio de la pobreza se apoyan mutuamente para sacar adelante a los "patojos". El padre Jean es otro ejemplo de un afecto maduro y responsable que decide velar por la madre de Apolonio cuando este la abandonó. El mismo Apolonio es beneficiario de personajes que buenamente lo ayudan sin conocerlo, pero que han visto en él al prójimo que necesita ayuda, como es el caso de Francisco Antonio Seco, el gerente del hotel que veló por Apolonio cuando este estuvo en el hospital en Santa Bárbara, Honduras. Estos ejemplos positivos de entrega desinteresada entran en la lógica del concepto del éxtasis que, según López Quintás, no empasta, no seduce, mantiene la distancia, es unidad fecunda (2011:42). Las experiencias de éxtasis generan alegría, luego entusiasmo, además de apertura y donación personal. El éxtasis permite la vivencia de la felicidad interior al conducir a la persona hacia la plenitud de vida. Una de las características fundamentales del éxtasis es la generosidad. El éxtasis de estos personajes hace posible los ámbitos fecundos de los grandes valores humanos.

Por todo lo anterior, se observa que no es que Apolonio no haya tenido experiencia cercana de buenas relaciones afectivas, ha visto sus beneficios, pero su odio y autosuficiencia le hacen desistir del encuentro personal; para él abrir su vida y su mundo a los demás es un acto riesgoso, de ser vulnerable. Al ser una persona sin vínculos, Apolonio no es capaz de construir una plenitud de vida, que solo se pude alcanzar en la medida en que las relaciones base sean fuertes y positivas: la familia, la amistad, el trabajo honesto, la vida interior.

\section{Conclusiones}

En este recorrido por las claves personalistas de la novela Apolonio se pudo evidenciar que esta obra tiene una importante densidad filosófica que se manifiesta en los diálogos y en el camino existencial de sus personajes, especialmente de Apolonio. Los conceptos del método lúdicoambital y otros conceptos de la filosofía personalista son útiles para comprender esta novela.

En el caso de este personaje, se observa que no hay un "viaje del héroe" o un recorrido de "aprendizaje"; lo que le va ocurriendo no lo aprovecha para reconstruir su estructura mental ni sus actos humanos; todo lo contario, la novela muestra el camino vertiginoso - de ascenso y caída estrepitosa- de este personaje que persiste en su orgullo, su odio y su razón. Al final se nos presenta a un Apolonio desarraigado, solo y vacío como fruto de una vida cerrada en sí misma. La actitud objetivista del personaje hace imposible la aparición de ámbitos creativos de convivencia que lo hubieran podido salvar de la soledad y la angustia final.

\section{Referencias}

Burgos, Juan Manuel. Introducción al personalismo. Madrid: Palabra, 2012. Impreso.

- Reconstruir a la persona. Ensayos personalistas. Madrid: Palabra, 2009. Impreso. 
Burgos, Juan Manuel., José Luis Cañas, J. Urbano Ferrer (eds.). Hacia una definición de la filosofía personalista. San José: Promesa, 2008. Impreso.

Domínguez Prieto, Xosé. Para ser persona. Madrid: Fundación Emmanuel Mounier, 2008. Impreso.

González Villanueva, Gustavo. Apolonio. Un político dentro de la posible realidad de América Latina. San José: Promesa, 2016. Impreso.
López Quintás, Alfonso. Literatura francesa del siglo XX. Sartre, Saint-Exupéry, Camus, Anouilh, Beckett. San José: Promesa, 2011. Impreso.

- Vértigo y éxtasis. Madrid: Rialp, 2006. Impreso.

Mires, Fernando. El pensamiento de Benedicto XVI. Santiago: LOM, 2006. Impreso.

Ospina, Helena y Gabriel Quesada (eds.). Literatura y personalismo. Una mirada profunda. San José: Promesa, 2014. Impreso. 
